\title{
A EXPERIÊNCIA CEARENSE QUE INSPIROU O PACTO NACIONAL PELA ALFABETIZAÇÃO NA IDADE CERTA
}

\author{
Adriana Ferreira Martins Alflen ${ }^{1}$ \\ Alboni Marisa Dudeque Pianovski Vieira ${ }^{2}$
}

\section{INTRODUÇÃO}

O sistema organizacional social desempenha papel importante na política educacional brasileira, a qual é condicionada a efetivas ações para atingir objetivos predeterminados, por meio de interações entre os múltiplos atores e os entes da federação, os diversos movimentos sociais e educacionais, um corpus burocrático-profissional, os estudantes e as agências internacionais e multilaterais.

O Pacto Nacional pela Alfabetização na Idade Certa constitui-se como um programa do governo federal, cujo eixo principal está na formação continuada do professor alfabetizador, que de forma colaborativa auxilia na transformação do cenário educacional para a superação do analfabetismo (BRASIL, 2012a).

O sistema educacional brasileiro é responsável pela garantia dos objetivos que se referem à educação básica. Nessa ótica, destaca-se a vigência de ações, na política educacional, visando suprir as necessidades básicas de aprendizagem e propiciar ensino de qualidade, além da erradicação do analfabetismo e da distorção idade/série. Ao analisar as ações da política educacional, “[...] em função do grande número de programas para superação do analfabetismo, e sua descontinuidade, é preciso pensar em otimizar recursos e qualificar melhor os alfabetizadores" (GATTI, 2004, p. 17).

Nessa realidade, muitos estudos vêm sendo desenvolvidos no sentido de favorecer a construção de políticas públicas que, de fato, revertam os indicadores de desempenho dos alunos em todos os sistemas de ensino no país e um dos caminhos apontados pelos pesquisadores é a estratégia da formação continuada de professores (GATTI, 2004; GATTI; BARRETO; ANDRÉ, 2011).

A política pública é uma condição de governabilidade, exclusiva do Estado, “[...] no que se

\footnotetext{
1 Licenciada em Pedagogia, mestre em Educação pela PPGE da PUCPR. Diretora de Departamento do Ensino Fundamental do Município de São José dos Pinhais/PR. adriana_alflen@ hotmail.com

${ }^{2}$ Licenciada em Pedagogia, bacharel em Direito, mestre em Gestão de Instituições de Educação Superior, mestre em Educação, doutora em Educação. Professora do Programa de Pós-Graduação em Educação (Mestrado e Doutorado) da Pontifícia Universidade Católica do Paraná. alboni@alboni.com
} 
refere a toda a sua extensão (formulação, deliberação, implementação e monitoramento)" (OLIVEIRA, 2010, p. 8). Portanto, as políticas públicas educacionais exercem o papel de orientar, regular e monitorar as unidades de ensino no território brasileiro, sendo acompanhadas pelo “desenvolvimento do próprio capitalismo" (OLIVEIRA, 2010, p. 8) e causando impacto na gestão educacional.

Segundo Azevedo (2004), a partir da década de 1980, as orientações internacionais de cunho neoliberal começaram a ser adotadas pelos países para a expansão do crescimento econômico. Nesse contexto de desenvolvimento econômico e globalizado, a educação "[...] é considerada um dos fatores mais importantes para a redução das desigualdades” (AZEVEDO, 2004, p. 15) na sociedade. Assim, as mudanças no aspecto econômico, o mundo do trabalho e a globalização interferem nas políticas sociais e em especial na gestão da educação, para obtenção de melhores resultados, eficiência e qualidade.

Conforme aponta Dourado (2010), as políticas de gestão da educação são influenciadas por marcos regulatórios, entre os quais se identificam diferentes atores e setores institucionais, com base em diretrizes, compromissos e objetivos globais. A política educacional é, assim, articulada sob os aspectos de perspectivas em escala nacional e mundial, nas quais se encontram os organismos multilaterais que preconizam suas orientações para a propagação do seu projeto global de educação.

Em tal perspectiva, Miguel e Vieira (2008) analisam a articulação da política educacional em que se estabeleceu o Plano Nacional para Educação no Brasil, a partir da Lei 9.394/96. Após 1996, as metas fixadas para os dez anos seguintes articulavam-se em sintonia com a Declaração Mundial sobre Educação para Todos, resultando em políticas públicas para a educação, bem como na formação continuada do docente para a demanda do mercado de trabalho, pela qual a política educacional é fortemente influenciada.

No que tange à política educacional para a alfabetização, busca-se conhecer as experiências de gestão para a educação no estado do Ceará, cujos objetivos foram os de superar o índice de analfabetismo e o déficit de aprendizagem de alunos do ciclo de alfabetização, nos dois primeiros anos da educação básica.

Foram consideradas no estudo, também, as diretrizes internacionais e nacionais visando a erradicação do analfabetismo, discutidas as políticas educacionais para os anos iniciais da educação básica e descrita a experiência cearense que serviu de inspiração ao PNAIC.

Assim, o estudo que deu origem a esse artigo baseia-se em pesquisa de caráter bibliográfico e documental, o qual aponta dados relevantes no que se refere à inspiração para o PACTO. 
O artigo está organizado em quatro seções: a primeira delas trata das diretrizes internacionais para o alcance global da meta na alfabetização de todos, como garantia do direito à educação; a segunda, das diretrizes nacionais na política educacional para a erradicação do analfabetismo; a terceira traz as experiências cearenses relativas ao programa para a formação continuada do professor alfabetizador; e, por último, a quarta, com a política educacional para alfabetização expressa no PNAIC e a sua semelhança com a estrutura do PAIC, no que se refere à formação continuada do professor alfabetizador e à idade certa para a alfabetização.

\section{DIRETRIZES PARA A ERRADICAÇÃO DO ANALFABETISMO}

\subsection{DIRETRIZES INTERNACIONAIS}

O compromisso para a erradicação do analfabetismo no Brasil foi assumido como política educacional, a partir da Conferência Mundial sobre Educação para Todos, em Jomtien (Tailândia), realizada no período de 5 a 9 de março de 1990 e patrocinada por quatro organismos internacionais: a Organização das Nações Unidas para a Educação, a Ciência e a Cultura (UNESCO), a Fundação das Nações Unidas para a Infância (UNICEF), o Programa das Nações Unidas para o Desenvolvimento (PNUD) e o Banco Mundial (SHIROMA; MORAES; EVANGELISTA, 2007). Nela, estiveram presentes representantes de 155 países para debates e reflexões sobre a educação, momento em que se evidenciou a necessidade do acesso à educação básica para a erradicação do analfabetismo (UNESCO, 2008, p. 31) e que resultou na Declaração Mundial sobre Educação para Todos.

Essa Declaração estabeleceu o Plano de Ação para Satisfazer às Necessidades Básicas de Aprendizagem para a garantia do direito à educação para todos, após constatar que 100 milhões de crianças não tiveram acesso ao ensino primário, sendo as meninas a faixa correspondente à metade dessa estimativa. Evidenciou-se ainda que 960 milhões de adultos eram analfabetos, dos quais “[...] dois terços correspondiam às mulheres" (UNESCO, 1990, p. 2).

Diante de tais constatações, apresentadas em números e realidades educacionais, a proposta da Conferência de Jomtien foi a de erradicar o analfabetismo e, a partir de 1990, a Unesco assumiu a responsabilidade de monitorar e acompanhar as ações, os avanços e as dificuldades a serem vencidas pelos países. Os sistemas de ensino dos países-membros foram direcionados a seguirem as orientações dos fóruns mundiais, a fim de atender às exigências e ao ordenamento de uma sociedade em constante transformação. Aos governos incumbiu realizar a avaliação do desempenho das metas estabelecidas quanto às diretrizes internacionais para a educação do século XXI. Em meio à globalização, a Comissão Econômica das Nações Unidas (CEPAL) e a Unesco, em 1992, 
orientaram a política para a educação, na qual os princípios de competitividade e equidade fundamentam as diretrizes para a educação (SANDER, 2008).

Ao assumir papel central na idealização da educação para o século XXI, a Unesco convocou especialistas do mundo todo para compor a Comissão Internacional sobre a Educação, à qual coube elaborar o Relatório Delors (DELORS, 1998). Esse relatório traz resultados das discussões realizadas e aponta as necessidades do contexto educacional, "[...] enfatizando o papel que a educação deveria assumir" (SHIROMA; MORAES; EVANGELISTA, 2007, p. 55).

O Relatório Delors identifica os ideais para o desenvolvimento do mundo globalizado e considera o conceito de qualidade na educação em pressupostos neoliberais, em que se articula com a noção de gerencialismo do processo educativo. A busca pela qualidade na educação “[...] implica em superar a crise de eficiência, eficácia e produtividade presentes nos sistemas de ensino e, por conseguinte, corrigir a improdutividade que perpassa a prática pedagógica e a gestão das unidades escolares" (AZEVEDO, 2011, p. 424).

Desse modo, a formação docente assume o centro das políticas educacionais no enfrentamento dos desafios do século XXI: assegurar a educação básica de qualidade e erradicar o analfabetismo.

\subsection{DIRETRIZES NACIONAIS}

Oliveira (2010) definiu o papel do Estado como expressão de um interesse amplo e articulado, no qual estão inseridos os sujeitos, em um contexto social e desigual. Para isso, é preciso que estejam expressos os interesses e os direitos que consagram o sujeito social.

A política educacional - tendo em vista as transformações e os interesses para a educação, que ocorrem em contexto amplo e global, de modo a causar impactos sobre a sociedade e revelar os desafios a serem superados - assumiu seu papel em assegurar o direito à cidadania, em pleno exercício de suas capacidades básicas para atuar na sociedade.

Em 1993, o Ministério da Educação (MEC) elaborou o Plano Decenal de Educação para Todos (1993-2003), articulado às resoluções aprovadas na Conferência Mundial de Educação para Todos (Jomtien), cujo objetivo mais amplo era “[...] assegurar, até o ano 2003, a crianças, jovens e adultos, conteúdos mínimos de aprendizagem que atendam as necessidades elementares da vida contemporânea" (BRASIL, 1993, p. 13). Esse objetivo, no entanto, não foi atingido, tanto assim que, em 2001, o país apresentou o índice de distorção idade/série de 35,3\% (BRASIL, 2014a).

Em 2001, foi instituído o Plano Nacional de Educação (PNE) pela Lei 10.172/2001, a qual estabelece prioridades, entre elas a erradicação do analfabetismo (BRASIL, 2001). Cada município foi orientado para que elaborasse o Plano Municipal de Educação a partir das diretrizes e metas 
desse PNE. Essas "[...] prioridades se constituíram hegemonicamente, pela adoção de políticas focalizadas, com forte ênfase no ensino fundamental, e pela efetivação de vários instrumentos e dispositivos, visando à construção de um sistema de avaliação da educação" (DOURADO, 2010, p. 683).

Além do PNE, a política educacional para a educação básica passou a apoiar-se nos resultados das avaliações em larga escala, como eixo norteador da qualidade do ensino ofertado. Essas avaliações estão definidas pela Portaria Ministerial no 931, de 21 de março de 2005, que regulamentou o Sistema de Avaliação Nacional da Educação Básica (SAEB) (BRASIL, 2005). Somando-se a essa ação, foi implementado o Plano de Metas Compromisso Todos pela Educação, criando-se o índice de Desenvolvimento da Educação Básica (IDEB), a partir do Decreto no 6.094, de 24 de abril de 2007, responsável pela avaliação da qualidade da educação básica para todos.

Ao se instituir as metas do Compromisso Todos pela Educação, foi determinada uma idade para a alfabetização, cabendo aos entes federados alfabetizar as crianças até, no máximo, oito anos de idade, a fim de aferir os resultados por exames específicos (BRASIL, 2007). Nesse caso, alfabetizar significa tornar a criança capaz de utilizar a leitura e a escrita, em suas necessidades básicas e para sua comunicação na vida social.

\section{EXPERIÊNCIAS CEARENSES NA GESTÃO DA POLÍTICA EDUCACIONAL}

O objetivo da pesquisa foi verificar se as ações desenvolvidas no âmbito da política educacional cearense para garantir a aprendizagem e melhorar a qualidade na educação básica, priorizando como meta a alfabetização na idade certa e tendo como uma das estratégias a formação continuada do professor alfabetizador, serviram de inspiração à proposta do Pacto Nacional pela Alfabetização na Idade Certa (PNAIC).

Destaca-se a experiência mencionada no livro Vencendo o desafio da aprendizagem nas séries iniciais: a experiência de Sobral/CE (BRASIL, 2005), que trata das mudanças na política do município para educação sob o efeito da "Lei de Diretrizes e Bases da Educação Nacional (LDB), dos Parâmetros Curriculares Nacionais (PCNs) e, sobretudo, do impacto causado pelo Fundo de Manutenção e Desenvolvimento do Ensino Fundamental (FUNDEF)” (BRASIL, 2005, p. 15).

As políticas para educação implementadas no país e, dentre elas, nos municípios da Região Nordeste, obtiveram “[...] fortalecimento do Projeto Nordeste, posteriormente ampliado para as regiões Norte e Centro-Oeste com a denominação de FUNDESCOLA” (MAIA, 2006, p. 42). Os impactos para a educação no município de Sobral ocorreram a partir do "[...] fundo, de maior volume de recursos financeiros aos municípios mais pobres e com maior número de matrículas" 
(MAIA, 2006, p. 89), estes disponibilizados pela nova LDB e pela Lei do Fundef.

O programa FUNDESCOLA é “[...] oriundo de um acordo de financiamento entre o Banco Mundial (BM) e o MEC, desenvolvido em parceria com as secretarias estaduais e municipais de Educação dos estados envolvidos”, cuja missão “[...] é o desenvolvimento da gestão escolar, com vistas à melhoria da qualidade das escolas públicas" (OLIVEIRA; FONSECA; TOSCHI, 2005, p. 128).

Na experiência ocorrida no município de Sobral, na primeira gestão do prefeito Cid Gomes (1997-2000), ganharam destaque as ações na política educacional para a educação básica, em que se priorizou a alfabetização dos alunos nas séries iniciais. Contudo, apesar dessas ações, em 2000, verificou-se "[...] que metade das crianças na $2^{\mathrm{a}}$ série não sabia ler” (BRASIL, 2005, p. 15). A reação a esse resultado veio com a aprovação da Lei 294, de 02 de fevereiro de 2001, que definiu o ensino fundamental de nove anos, com ingresso da criança aos seis anos de idade (SOBRAL-CE, 2001). A estratégia adotada pelo município para a consecução desse objetivo baseou-se em três pilares para a gestão: “[...] mudança da prática pedagógica, fortalecimento da autonomia da escola e monitoramento dos resultados da aprendizagem com base em indicadores" (BRASIL, 2005, p. 16).

A prática de monitoramento da aprendizagem, a partir das avaliações externas, oportunizou aos professores e gestores, “[...] estratégias próprias para o acompanhamento cotidiano de seus resultados, com a adoção do procedimento de avaliar internamente a aprendizagem dos alunos a cada mês" (BRASIL, 2005, p. 44). Em 06 de janeiro de 2004, o município de Sobral sancionou a Lei $\mathrm{n}^{\circ} 8$, instituindo e priorizando como política educacional para a alfabetização as capacidades básicas para a aprendizagem concernentes à leitura e à escrita. Desse modo, compreendeu-se como necessidade a formação continuada do docente alfabetizador e a importância em desenvolver sua capacidade como mediador da aprendizagem, com vistas a contribuir para o processo de emancipação do aluno (BRASIL, 2005).

A experiência no município de Sobral estendeu-se a outros municípios do estado do Ceará que, segundo dados do PNAD, no ano de 2005, apresentou o índice de analfabetismo em torno de $14 \%$, considerado acima da taxa nacional, que correspondia a 8\%. Sobral inspirou "[...] as gestões municipais do País a implementar políticas que tenham o objetivo de garantir o direito à aprendizagem" (BRASIL, 2005, p. 18).

Em 2007, constatou-se que “[...] 15\% dos alunos do $2^{\circ}$ ano do ensino fundamental do Ceará liam e compreendiam um pequeno texto, e somente $42 \%$ conseguiram produzir na escrita" (GUERREIRO, 2013, p. 1). Assim sendo, por meio da Secretaria de Educação do Estado do Ceará (SEDUC), os municípios assumiram a execução do PAIC em parceria com a Associação dos 
Municípios do Estado do Ceará (APRECE), Associação para o Desenvolvimento dos Municípios do Estado do Ceará (APDMCE), Fundo das Nações Unidas para a Infância (UNICEF), União Nacional dos Dirigentes Municipais de Educação (UNDIME/CE) e as universidades, cujo objetivo foi o de oferecer assessoria técnica aos municípios por um período de quatro anos, visando melhorar seus indicadores de aprendizagens e alfabetizar os alunos até o final do $2^{\circ}$ ano (CEARÁ, 2007).

Os municípios cearenses, ao aderir ao PAIC, assumiram a condição de protagonistas junto ao Plano de Metas Compromisso Todos pela Educação. Para atingir as metas, o PAIC estruturou-se em cinco eixos: I. Educação Infantil; II. Gestão Pedagógica - Alfabetização e Formação de Professores; III. Gestão da Educação Municipal; IV. Formação do Leitor; V. Avaliação Externa de Aprendizagem. Essa intervenção sistêmica e articulada foi autorizada no art. $1^{\circ}$, da Lei 14.026, que instituiu o PAIC, “[...] por meio do qual o Estado, em cumprimento ao regime de colaboração, poderá[ia] prestar cooperação técnica e financeira aos municípios cearenses, com vistas à melhoria dos resultados de aprendizagem" (CEARÁ, 2007).

O governo cearense, ao assinar o pacto de cooperação com o PAIC, envolveu ações como oferta de recursos pedagógicos aos alunos do ciclo de alfabetização do $1^{\circ}$ e $2^{\circ}$ anos do ensino fundamental, formação do professor alfabetizador e a compreensão de que o domínio da leitura e da escrita é condição básica necessária para o aluno em outras aprendizagens na vida. Ressalta-se, ainda, o incentivo à leitura por meio do programa, como também o monitoramento da alfabetização por meio da avaliação (GATTI; BARRETO; ANDRÉ, 2011).

A experiência do estado do Ceará, em gestão da educação básica, tendo como relevância a alfabetização, ganhou destaque junto ao MEC, visto que os municípios do estado trabalharam em regime de cooperação na política educacional para a alfabetização no sistema estadual de educação.

\section{PACTO NACIONAL PELA ALFABETIZAÇÃO NA IDADE CERTA}

Esta seção propõe-se a analisar três categorias que contextualizam a inspiração do programa do governo federal, denominado Pacto Nacional pela Alfabetização na Idade Certa (PNAIC), no programa desenvolvido pelo governo do estado do Ceará. As categorias destacadas referem-se à alfabetização na idade certa, à formação continuada do professor alfabetizador e ao regime de colaboração.

É evidente que, nas relações do trabalho pedagógico que se efetivam entre as unidades de ensino, compreende-se a necessidade de uma articulação com uma política nacional de formação continuada dos/das profissionais da educação, para que participem efetivamente das ações voltadas 
à alfabetização. Essa política, de acordo com o documento final da Conferência Nacional de Educação (CONAE), realizada em 2010, deve garantir:

[...] a formação baseada na dialética entre teoria e prática, valorizando a prática profissional como momento de construção e ampliação do conhecimento, por meio da reflexão, análise e problematização do conhecimento e das soluções criadas no ato pedagógico. Assim, por meio de programas, ações e cursos, envolvendo as instituições de formação, o MEC e os sistemas de ensino, essa política deve propiciar o desenvolvimento da capacidade de reflexão, oferecendo perspectivas teóricas de análise da prática, para que os/as profissionais nela se situem e compreendam, também, os contextos históricos, sociais, culturais e organizacionais em que atuam (CONAE, 2010, p. 79).

\subsection{Alfabetização na Idade Certa}

Atendendo ao exposto pela CONAE (2010) e ao contido no PNE (2014-2024) - nos quais uma das metas é a alfabetização - surgiu o Pacto Nacional pela Alfabetização na Idade Certa (PNAIC) do governo federal, instituído pela Portaria $n^{\circ}$ 867, de 04 de julho de 2012, do Ministério da Educação, que, em seu art. $5^{\circ}$, estabelece a meta de serem as crianças alfabetizadas no máximo até os oito anos de idade e ou ao final do terceiro ano do ensino fundamental (BRASIL, 2012a).

Diferentemente, a experiência cearense, desenvolvida no PAIC, definira como compromisso a alfabetização até no máximo os sete anos de idade e ao final do $2^{\circ}$ ano e "[...] foi assumida como prioridade pelo governo estadual e transformada em política pública” (GOMES, 2013, p. 12) para todos os municípios cearenses.

Para Soares (2010), a alfabetização até os oito anos de idade é possível, desde que o domínio do sistema ortográfico esteja em um processo satisfatório e que as habilidades de leitura e escrita avaliadas sejam expressas nas situações sociais próprias para a etapa correspondente à infância. Observa-se que "[...] em sociedades em que a escrita tem forte presença, a criança inicia seu processo de alfabetização muito antes de chegar à escola" (SOARES, 2010, p. 35), pois está imersa em um contexto cultural no qual a leitura e a escrita fazem parte da comunicação e da interação social.

Por sua vez, o PNAIC foi instituído pelo MEC, em 2008, após um processo histórico com ampla generalização de intenções, às quais se seguiram diretrizes legislativas que definiram essa política educacional. Esse programa orienta o ingresso da criança de seis anos no Ensino Fundamental e auxilia na compreensão da gestão pedagógica, com o olhar voltado às crianças do $1^{\circ}$ ano do Ensino Fundamental como parte integrante de um ciclo de três anos de duração, denominado “ciclo da infância". Os três anos iniciais são identificados como um período voltado à alfabetização 
e ao letramento, no qual deve ser assegurado também o desenvolvimento das diversas expressões e o aprendizado das áreas de conhecimento (BRASIL, 2008).

Diversamente do PNAIC, o PAIC, ao estabelecer a idade máxima para a alfabetização aos sete anos e ao final do $2^{\circ}$ ano, não contemplou o ciclo de alfabetização do $1^{\circ}$ ao $3^{\circ}$ ano, mas envolveu, em seu âmbito, uma política de colaboração entre o Estado, seus municípios e estabelecimentos de ensino para o alcance da alfabetização. No que tange à gestão educacional cearense, para garantia da aprendizagem e cooperação de forma técnica e financeira, firmaram-se acordos "[...] com universidades públicas e seus institutos ou fundações universitárias de pesquisa e pós-graduação e, ainda, com instituições de fomento à pesquisa" (CEARÁ, 2007) para auxiliar na gestão do processo educacional, bem como na formação continuada do professor.

\subsection{Formação continuada do professor alfabetizador}

$\mathrm{Na}$ estrutura do Pacto, as ações concentram-se em quatro eixos, sendo um deles corresponde à formação continuada, a qual é direcionada ao aperfeiçoamento dos professores alfabetizadores que atuam nos três primeiros anos do ensino fundamental. De certa maneira, a política para a formação continuada no PAIC, que iniciou no município de Sobral-CE, garantiu, aos professores alfabetizadores, encontros para o desenvolvimento de estratégias, entre as quais a "[...] vivência das atividades propostas para a rotina da sala de aula, experimentação dos materiais didáticos a serem usados nas aulas" e ao "[...] monitoramento dos resultados de aprendizagem dos alunos" (BRASIL, 2005, p. 37).

O PNAIC, no processo de formação continuada docente, tem como princípio desenvolver a autonomia e os saberes que permitam ao professor ir em busca de meios e instrumentos que o auxiliem em sua prática pedagógica e em seu desenvolvimento profissional, a fim de garantir a efetiva aprendizagem dos alunos (BRASIL, 2015). Assim, a formação continuada não possui caráter prescritivo e prioriza “[...] encaminhamentos metodológicos que possibilitem o desenvolvimento dos direitos de aprendizagem dentro do ciclo de alfabetização" (BRASIL, 2015, p. 22).

\subsection{REGIME de colaboração}

No que se refere à gestão do trabalho pedagógico no PNAIC, destaca-se a avaliação, cujo objetivo é aferir o êxito das metas. Um dos instrumentos utilizados para avaliar é a Provinha Brasil, que "[...] é aplicada pelos professores no início e ao final do $2^{\circ}$ Ano do ciclo de alfabetização, tendo como objetivo avaliar o nível do sistema alfabético de escrita, bem como as habilidades de leitura que as crianças dominam” (BRASIL, 2012b, p. 33). 
Além da Provinha Brasil, acrescenta-se o indicador da Avaliação Nacional de Alfabetização (ANA): “A Prova ANA, é aplicada pelo INEP ao final do $3^{\circ}$ Ano, tendo como objetivo avaliar o processo das habilidades básicas do aluno, nas áreas de Língua Portuguesa e Matemática que contempla o $3^{\circ}$ Ano (BRASIL, 2012b).

Em face desse processo, a formação continuada do docente deve ser pautada nas relações sobre resultados, em que se evidencie seu papel no processo pedagógico como fator condicionante na transformação social da realidade em que impera a baixa qualidade no ensino.

É importante destacar o eixo gestão, controle e mobilização social no PNAIC, sob a forma organizacional, em quatro instâncias, as quais são compostas por: um Comitê Gestor Nacional, uma coordenação institucional em cada Estado, uma coordenação estadual e outra municipal, sendo responsáveis pela implementação, gestão, supervisão e monitoramento das ações do Pacto (BRASIL, 2012a).

No caso cearense, a prioridade dada à formação continuada docente no PAIC surgiu a partir de uma ampla mobilização social gerada pelo Comitê Cearense para a Eliminação do Analfabetismo Escolar, que coloca o tema na berlinda e convoca os gestores públicos à ação. A política educacional cearense, ao instituir o PAIC, articulou a gestão educacional para a alfabetização, em um regime de colaboração entre Estado e Municípios, “[...] sem esperar por uma lei complementar que regulamentasse" (GOMES, 2013, p. 13).

Portanto, considerando o regime de colaboração entre o Estado do Ceará e seus Municípios, o PAIC fortaleceu "[...] a capacidade institucional dos Municípios para formular e implementar políticas públicas educacionais" (GOMES, 2013, p. 13) para o alcance da alfabetização, o qual serviu de inspiração ao programa do governo federal intitulado como PNAIC.

No quadro a seguir, são apresentadas as diferenças na organização dos Programas PAIC e PNAIC, a partir das categorias selecionadas:

QUADRO 1 - DIFERENÇAS ENTRE O PAIC E O PNAIC

\begin{tabular}{|c|c|c|}
\hline DIFERENÇAS & PAIC & PNAIC \\
\hline $\begin{array}{l}\text { IDADE PARA A CRIANÇA } \\
\text { SER ALFABETIZADA }\end{array}$ & $\begin{array}{l}\text { Compromisso em alfabetizar até } \\
\text { no máximo os sete anos de } \\
\text { idade e ao final do } 2^{\circ} \text { ano }\end{array}$ & $\begin{array}{l}\text { A alfabetização até no máximo os oito } \\
\text { anos de idade e/ou ao final do terceiro } \\
\text { ano do ensino fundamental, com ênfase } \\
\text { no ciclo de alfabetização. }\end{array}$ \\
\hline $\begin{array}{l}\text { FORMAÇÃO CONTINUADA } \\
\text { DO } \\
\text { ALFABETIZADOR }\end{array}$ & $\begin{array}{l}\text { Relaciona-se à garantia do } \\
\text { direito efetivo à aprendizagem, } \\
\text { sendo o eixo norteador da } \\
\text { política educacional }\end{array}$ & $\begin{array}{l}\text { Estabelece os direitos de aprendizagem, } \\
\text { como diretrizes, os quais se desdobram } \\
\text { em objetivos a serem alcançados e } \\
\text { orientam também o trabalho de formação } \\
\text { continuada do docente, mobilizando } \\
\text { saberes. }\end{array}$ \\
\hline $\begin{array}{l}\text { REGIME } \\
\text { COLABORAÇÃO }\end{array}$ & $\begin{array}{l}\text { A mobilização social foi gerada } \\
\text { pelo Comitê Cearense para a }\end{array}$ & $\begin{array}{l}\text { A mobilização ocorreu por um Comitê } \\
\text { Gestor Nacional, uma coordenação }\end{array}$ \\
\hline
\end{tabular}




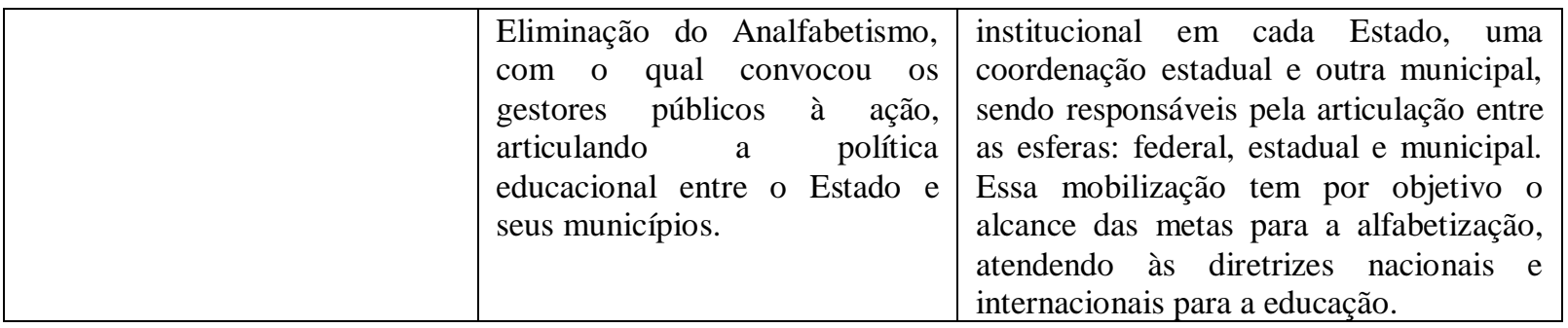

Fonte: as autoras, 2016.

\section{CONSIDERAÇÕES FINAIS}

Os estudos indicam que a Conferência de Jomtien, em 1990, da qual resultou a Declaração Mundial para Todos, constatou um alto índice de analfabetismo em alguns países, entre eles, o Brasil. Assim, a educação passou a ser o centro da atenção mundial, como direito de todos e fundamental para o desenvolvimento econômico e a equidade social dos países em meio à globalização econômica.

Diante desse diagnóstico, após a Conferência de Jomtien, foi elaborado o Plano para a Satisfação das Necessidades Básicas para a Educação e a Unesco, como norteadora do projeto social global para a educação, estabeleceu orientações para as políticas educacionais nacionais, com ações e estratégias voltadas à erradicação do analfabetismo.

Assim, em 1993, o governo brasileiro, para atender ao compromisso assumido na Declaração Mundial sobre Educação para Todos, elaborou o Plano Decenal (1993-2003), com o objetivo de garantir a aprendizagem para todos, a ser alcançada até o ano de 2003. O MEC, ao elaborar o Plano Decenal de Educação para Todos, estabeleceu a erradicação do analfabetismo como política pública para a educação, considerando-a como estratégia para elevar a qualidade na educação e garantir o direito à aprendizagem, em sintonia com as diretrizes internacionais para a educação. Para a sua consecução, seriam necessárias ações de forma articulada e em regime de colaboração entre as esferas governamentais.

Entretanto, mesmo com as ações articuladas na política educacional para a garantia da aprendizagem, o Brasil, em 2000, não conseguiu erradicar o analfabetismo e apresentou um índice considerável de distorção na relação idade-série, o que demonstra que a meta global para a educação não foi alcançada.

Com a edição do PNE (2001-2010), em 2001, estabeleceu-se como uma das prioridades a erradicação do analfabetismo. Na articulação das diretrizes e metas para educação - entre o mundial, o nacional e o local -, considerou-se prioridade a competência em alfabetizar, sendo a 
formação continuada docente fundamental para a garantia do direito à aprendizagem. Para monitoramento desse processo, foi implantado um sistema de avaliação que teve como eixo norteador a qualidade na educação.

Ao investigar as experiências cearenses no âmbito da política educacional desenvolvida no PAIC, constatou-se que o estado do Ceará e seus municípios instituíram uma política para a alfabetização. A estratégia para o alcance desse objetivo centrou-se na gestão por resultados, com monitoramento da aprendizagem da leitura e da escrita.

Observou-se, por meio das ações desenvolvidas no PNAIC, que em sua estrutura, há coerência com a política educacional cearense, no sentido de estabelecer a alfabetização na idade certa como prioridade e um regime de colaboração para o alcance das metas estabelecidas entre os entes federados.

A política educacional cearense foi pioneira ao estabelecer a alfabetização para todas as crianças no máximo aos sete anos. Diferentemente do PNAIC, não considerou o ciclo de alfabetização em sua política e, na formação continuada do professor, buscou auxiliar com encaminhamento metodológico a ser aplicado no processo de ensino e aprendizagem. Por seu turno, o PNAIC deu ênfase ao ciclo de alfabetização e apostou em uma formação do professor alfabetizador de caráter não prescritivo, com a mobilização de saberes docentes voltada à constituição da identidade do professor.

A experiência na política educacional cearense foi considerada pelo Inep como exitosa ao colaborar com a garantia do direito à aprendizagem. Assim, esta auxiliou na inspiração das propostas do PNAIC em âmbito federal, cujas ações ocorrem em regime de colaboração entre governo federal, estados, municípios e unidades de ensino da educação básica. 


\section{REFERÊNCIAS}

AZEVEDO, Janete M. Lins de. A educação como política pública. 3. ed. Campinas: Autores Associados, 2004.

Notas sobre a análise da gestão da educação e da qualidade do ensino no contexto das políticas educativas. RBPAE, v. 27, n. 3, p. 361-588, set./dez. 2011. Disponível em: <www.seer.ufrgs.br/rbpae/article/download/ 26412/15404>. Acesso em: 14 maio 2016.

BRASIL. Plano decenal de educação para todos: 1993-2003. Brasília, DF: MEC 1993. Disponível em: <http://www. dominiopublico.gov.br/download/texto/me002599.pdf>. Acesso em: 08 jul. 2016.

. Lei 10.172, de 9 de janeiro de 2001, que estabelece o Plano Nacional de Educação. Diário Oficial da União, DF, s.n., p. 1-20, jan. 2001. Seção 1. Disponível em: <https://www.planalto.gov.br/ccivil_03/leis/leis 2001/110172. htm>. Acesso em: 10 jul. 2016.

Portaria no 931, de 21 de março de 2005. Diário Oficial da União. Brasília, DF, n. 55, p. 17, 22 mar. 2005. Seção 1. Disponível em: <http://download.inep.gov.br/educacao_basica/prova_brasil_saeb/downloads/Port931_ 21MAR05.pdf>. Acesso em: 14 jul. 2016.

Instituto Nacional de Estudos e Pesquisas Educacionais Anísio Teixeira. Vencendo o desafio da aprendizagem nas séries iniciais: a experiência de Sobral/CE. Brasília: Instituto Nacional de Estudos e Pesquisas Educacionais Anísio Teixeira, 2005. Disponível em: 〈http://www.publicacoes.inep.gov.br/portal/download/432>. Acesso em: 09 jul. 2016.

Lei 11.494 de 20 de junho de 2007. Regulamenta o Fundo de Manutenção e Desenvolvimento da Educação Básica e de Valorização dos Profissionais da Educação - FUNDEB, de que trata o art. 60 do Ato das Disposições Constitucionais Transitórias; altera a Lei n ${ }^{\circ}$ 10.195, de 14 de fevereiro de 2001; revoga dispositivos das Leis nos 9.424, de 24 de dezembro de 1996, 10.880, de 9 de junho de 2004, e 10.845, de 5 de março de 2004; e dá outras providências. Diário Oficial da União. Brasília, DF, p. 7, 21 de jun. de 2007.Seção 1. Disponível em: <http://www.planalto.gov.br/ ccivil_03/_Ato2007-2010/2007/Lei/L11494.htm>. Acesso em: 09 jul. 2016.

. Ministério da Educação. Conselho Nacional de Educação. Parecer no 4 de 2008: Orientação sobre os três anos iniciais do Ensino Fundamental de nove anos. Diário Oficial da União, Brasília, DF, 10 de junho de 2008. Disponível em: <http://portal.mec.gov.br/cne/arquivos/pdf/2008/pceb004_08.pdf>. Acesso em: 20 abr. 2016.

Portaria n 867 de 04 de julho de 2012. Institui o Pacto Nacional pela Alfabetização na Idade Certa e as ações do Pacto e define suas diretrizes gerais. Diário Oficial da União. Brasília, DF, n. 129, p. 22-23, 05 jul. 2012 a. Seção 1. Disponível em: 〈http://www.lex.com.br/legis_23490618_PORTARIA_N_867_DE_4_DE_JULHO_DE_2012.aspx>. Acesso em: 10 ago. 2016.

Ministério da Educação. Pacto pela Alfabetização na Idade Certa: Brasil do Futuro com o começo que ele merece. Brasília, DF, 2012b. Disponível em: 〈http://pacto.mec.gov.br/images/pdf/pacto_livreto.pdf〉. Acesso em: 16 ago. 2016. _. Ministério da Educação. Consulta Pública. Relatório Educação para Todos no Brasil $2000-2015$. Versão Preliminar, 2014a. Disponível em: <http://portal.mec.gov.br/index.php?option=com_docman\&view=download \&alias=15774-ept-relatorio-06062014\&Itemid=30192>. Acesso em: 12 maio 2016.

Lei $n^{\circ}$ 13.005, de 24 de junho de 2014. Aprova o Plano Nacional de Educação - PNE e dá outras providências. Diário Oficial da União. Brasília, DF, p. 1, 26 jun. 2014b, Edição extra. Seção 1. Disponível em: <http://www.planalto.gov.br/ccivil_03/_Ato2011-2014/2014/Lei/L13005.htm>. Acesso em: 14 jun. 2016.

Conferência Nacional de Educação (CONAE). Construindo o Sistema Nacional articulado de Educação: o Plano Nacional de Educação, diretrizes e estratégias; Documento Final. Brasília, DF: MEC, 2010. 164p. Disponível em: <http://conae.mec.gov.br/images/stories/pdf/pdf/documetos/documento final sl.pdf>. Acesso em: 13 jul. 2016.

Ministério da Educação. Pacto Nacional pela Alfabetização na Idade Certa. Interdisciplinaridade no ciclo de alfabetização. Caderno de Apresentação. Brasília. 2015. DF. Disponível em: <http://pacto.mec.gov.br/images/pdf/ Cadernos_2015/cadernos_novembro/pnaic_cad_apresentacao.pdf>. Acesso em: 13 ago. 2016.

CEARÁ. Lei no 14.026 de 17 de dezembro de 2007. Cria o Programa Alfabetização na Idade Certa - PAIC, de cooperação técnica e incentivo para melhoria dos indicadores de aprendizagem nos municípios cearenses e dá outras providências. Diário Oficial do Estado, Ceará- Fortaleza, n. 239, p. 1-2, 19 de dezembro de 2007.

DELORS, Jacques. Educação: um tesouro a descobrir. São Paulo: Cortez; UNESCO, 1998.

DOURADO, Luiz Fernandes. Avaliação do Plano Nacional de Educação 2001-2009: questões estruturais e conjunturais de uma política. Educação \& Sociedade, Campinas, v. 31, n. 112, p. 677-705, jul./set. 2010. 
GATTI, Bernadete Angelina. Estudos quantitativos em educação. Educação e Pesquisa, São Paulo, v. 30, n. 1, p. 1130, abr. 2004.

GATTI, Bernadete Angelina; BARRETO, Elba Siqueira de Sá; ANDRÉ, Marli Eliza Dalmazo de Afonso. Políticas docentes no Brasil: um estado da arte. Brasília/DF: UNESCO, 2011.

GOMES, Ana Valeska Amaral. Alfabetização na idade certa: garantir a aprendizagem no início do ensino fundamental. Consultoria Legislativa. Brasília-DF. 2013. Disponível em: <http://www2.camara.leg.br/documentos-e-pesquisa/ publicacoes/estnottec/areas-da-conle/tema11/cp13004.pdf>. Acesso em: 12 jul. 2016.

GUERREIRO, Carmen. Ceará, o berço do pacto. Revista Educação, São Paulo, n. 193, 2013. Disponível em: <http:// www.revistaeducacao.com.br/ceara-o-berco-do-pacto/>. Acesso em: 13 jul. 2016.

MAIA, Maurício Holanda. Aprendendo a marchar: os desafios da gestão municipal do ensino fundamental e da superação do analfabetismo escolar. Tese (Doutorado) - Universidade Federal do Ceará, Fortaleza, 2006.

MIGUEL, Maria Elisabeth Blanck; VIEIRA, Alboni Marisa Dudeque Pianovski. As políticas educacionais e a formação continuada do professor. Revista HISTEDBR on-line. Campinas, n.31, p.127-141, set. 2008. Disponível em: <http://www.histedbr.fe.unicamp.br/revista/edicoes/31/art10_31.pdf >. Acesso em: 13 jul. 2016.

OLIVEIRA, Adão Francisco de. Políticas públicas educacionais: Conceito e contextualização numa perspectiva didática. In: OLIVEIRA, Adão Francisco de; PIZZIO, Alex; FRANÇA, George (Org.). Fronteiras da educação: desigualdades, tecnologias e políticas. Goiás: Editora PUC, 2010. p. 93-99.

OLIVEIRA, João Ferreira de; FONSECA, Marília; TOSCHI, Mirza Seabra. O programa FUNDESCOLA: concepções, objetivos, componentes e abrangência - a perspectiva de melhoria da gestão do sistema e das escolas públicas. Educação \& Sociedade, Campinas, v. 26, n. 90, p. 127-147, jan./abr. 2005. doi.org/10.1590/S0101-73302005000 100006

SANDER, Benno. Educação na América Latina: Identidade e globalização. Educação, Porto Alegre, v. 31, n. 2, p. 157165, maio/ago. 2008. Disponível em: 〈http://www.unisul.br/catedra/docs/b00fe065f942487097284270bd515e8a.pdf>. Acesso em: 13 abr. 2016.

SOARES, Magda Becker. Por uma alfabetização até aos oito anos de idade: De olho nas metas 2010. Meta 2. Disponível em: 〈http://www.todospelaeducacao.org.br//arquivos/biblioteca/artigo_alfabetizacao.pdf >. Acesso em: 22 jun. 2016.

SOBRAL. Lei 294 de 02 de fevereiro de 2001. Institui na rede de ensino do município de Sobral, o ensino fundamental com duração de 09 (nove) anos, e dá outras providências. Diário Oficial Municipal. Sobral-CE. 26 de março de 2001. Disp. em: 〈http://cm-sobral.jusbrasil.com.br/legislacao/712737/lei-294-01〉. Acesso em: 12 ago. 2016.

SHIROMA, Eneida Oto; MORAES, Maria Célia M. de; EVANGELISTA, Olinda. Política Educacional. 4. ed. Rio de Janeiro: Lamparina, 2007.

UNESCO. Declaração Mundial sobre Educação para Todos: Satisfação das necessidades básicas de aprendizagem. Jomtien, 1990. Disponível em: 〈http://unesdoc.unesco.org/images/0008/000862/086291por.pdf〉. Acesso em: 17 ago. 2016.

. Alfabetização de jovens e adultos no Brasil: lições da prática. Brasília, DF: UNESCO, 2008. Disponível em: <http://unesdoc.unesco.org/images/0016/001626/162640por.pdf >. Acesso em: 20 ago. 2016. 


\section{RESUMO}

Este artigo investiga as experiências educacionais realizadas na educação básica do Ceará, que serviram de base ao Pacto Nacional pela Alfabetização na Idade Certa (PNAIC), instituído pelo Ministério da Educação, em 2012. Foram consideradas diretrizes e políticas educacionais para os anos iniciais da educação básica, além da experiência cearense (Pacto pela Alfabetização na Idade Certa - PAIC). A pesquisa, bibliográfica e documental, de natureza qualitativa, fundamentou-se nos estudos de Azevedo (2004) e Dourado (2010). Foram também analisados a legislação pertinente e os documentos relacionados à experiência cearense e ao PNAIC. Os resultados obtidos evidenciaram que o PAIC e o PNAIC tratam, com prioridade, da alfabetização e têm como estratégia a formação continuada do professor alfabetizador.

Palavras-chaves: Alfabetização. Formação de professores. Políticas educacionais.

\section{THE CEARENSE EXPERIENCE THAT INSPIRED THE NATIONAL PACT FOR LITERACY AT THE RIGHT AGE}

\section{ABSTRACT}

This article investigates the educational experiences carried out in the basic education in Ceará that supported the National Pact for Literacy at the Right Age (PNAIC), established by the Ministry of Education in 2012. As such, the guidelines and educational policies for the initial years of basic education were considered, in addition to the Cearense experience (Pact for Literacy at the Right Age - PAIC). The qualitative research, bibliography and documentary was based on the studies by Azevedo (2004) and Dourado (2010). The relevant legislation and documents related to the Cearense experience and PNAIC were also analyzed. The results showed that the PAIC and PNAIC deal, primarily, with literacy, and have a strategy of continuous training of the literacy teacher.

Keywords: Educational politicies. Literacy. Teachers training.

\section{LA EXPERIENCIA CEARENSE QUE INSPIRÓ EL PACTO NACIONAL POR LA ALFABETIZACIÓN A LA EDAD CORRECTA}

\section{RESUMEN}

Este artículo investiga las experiencias educativas llevadas a cabo en la enseñanza fundamental de Ceará que servirán como base para el Pacto Nacional por la Alfabetización a la Edad Correcta (PNAIC), establecido por el Ministerio de Educación en 2012. Para esto, se tomaron en cuenta las directrices y políticas educacionales para los primeros años de la educación básica, además de la experiencia de Ceará (Pacto por la Alfabetización a la Edad Correcta - PAIC). La investigación, bibliográfica y documental, de naturaleza cualitativa, se basó en los estudios de Azevedo (2004) y Dourado (2010). También se analizó la legislación pertinente y los documentos relacionados con la experiencia de Ceará y el PNAIC. Los resultados alcanzados mostraron que el PAIC y el PNAIC tratan con prioridad la alfabetización y tienen como estrategia la capacitación continua de los alfabetizadores.

Palabras-clave: Alfabetización. Formación de profesores. Políticas educacionales. 